\title{
GAME: General Aggression Model in Education
}

\author{
Dr. Tanu Tandon ${ }^{1}$
}

\begin{abstract}
:
Women in India have been victim of violence and discrimination since ages but this aggression has also led to empowerment of women in some cases. This study deals with study of such aggressive women who transformed their aggression to empowerment. Grounded theory methodology has been used to explore and understand the process and role of education in transformation. This study focuses on route aggression takes and role of education in channelizing the aggressive energy so as to lead to empowerment.

General Aggression Model (GAM) given by Anderson and Bushman (2002) is a dynamic, social, cognitive developmental model which draws heavily on social-cognitive and social learning theories. Aggression depends on how an individual perceives and interprets his/her environment and people there in, this model has been revised and a new model has been devised namely General Aggression Model in Education or GAME, which shows path towards empowerment from aggression.
\end{abstract}

Keywords: General Aggression Model, Education

Status of women in India is sort of a paradox. On one side are examples of women power and on another hand we see women being exploited and used as commodities. Uttar Pradesh and Delhi are the places where crime against women is highest and it's an irony that both had Women chief ministers. These stark opposite examples set me thinking, the same states which have women as victims have given rise to most powerful women. I wondered whether the aggression against injustice and discrimination made women empowered. What has been the role of education in the lives of aggressive empowered women? Has education played any role in attainment of empowerment?

To find answers to my queries, I realized that I have to study the aggressive empowered women closely; in their socio cultural context therefore I adopted Qualitative approach and used Grounded Theory Methodology (GTM) for conducting my research.

I selected seven aggressive empowered women symbolizing 'Strength', 'Passion', 'Courage', 'Determination', 'Daring', 'Compassion' and 'sincerity' and generated data using open ended interviews, conversations, participant observations.

${ }^{1}$ Asst Professor, Amity Institute of Education, Amity University, Lucknow

(C) 2015 I T Tandon; licensee IJIP. This is an Open Access Research distributed under the terms of the Creative Commons Attribution License (http://creativecommons.org/licenses/by/2.0), which permits unrestricted use, distribution, and reproduction in any Medium, provided the original work is properly cited. 
The data were analyzed using GTM procedures namely, coding, writing memos, forming sub categories and categories. Through numerous codes, fifteen sub categories were formed which gave rise to five categories which formed the core category "Transcending the Aggressive Self to Empowered Self through Education"

Transcending the 'self' has been a journey, an ever going, ever-growing journey of woman from state of helplessness to emancipation. It has been an awakening and enlightening process for the women, under study. Their Journey has been to the 'self', which has taken them inside themselves, to know their desires, wishes and to acknowledge themselves as competent woman. The journey has been also about 'self', to know about their strengths, their rights, status and their place in their social world and society at large. It helped them to analyze their situations and work upon improving them. This journey has also been for the 'self ', to change their 'self' for the better, to bring changes in their life and to make their mark in their world and get their voices heard. It has been a well rewarding journey, where in they have not travelled alone, but with their families, society and have tried to stretch their boundaries, reach beyond themselves and have not only empowered themselves but also those around them, achieving emancipation in return.

Their journey from aggression to empowerment started with awareness. Awareness about their own emotions of 'self pity', 'loneliness', 'low self esteem', feelings of being 'un loved' and 'un desired', of acknowledging the discrimination and oppression being inflicted upon them. Being aware of their position and their rights made them more sensitive about the disparity that existed between the two, which built up the aggression in them even more. Understanding of their plight and deprivation made them raise their voices against injustice done to them and demand their rights as woman. Analysis of their circumstances gave them insight about their aggression and causes behind them. This in turn helped these women to look at their aggression objectively and rationally. Women aggression has relational context, various studies have proved, women are more likely to aggress in situation congruent to gender role orientation, such as family settings. In fact, strong evidence of women aggression have been found in intimate relationships and threat to a woman's self concept and self definition causes build up of aggression. Participants of my study, felt the same when they were rejected by their husbands and families, this was a blow to their self esteem and self concept. The response of one of the participant, Promila "I was treated like a Cattle" says much more than her words, it reflects how she was treated and more importantly the effect this treatment had on her, lowering her dignity and giving her a feeling of being 'used', like a non human entity, reducing her to be like an animal, reason enough for being aggressive.

Jack (1991, 1999) has suggested in his studies that most critical factors affecting aggression arousal and expression are in interpersonal context. Fehr and colleagues (1999) surmise that "women's greater propensity to be angered in close relationships, may reflect their greater motivation to achieve intimacy in these relationship, as well as their reported tendency to derive self esteem from close relationships."

A woman's world is her home where as a man has a larger context, in form of social world to prove his authority, therefore woman's self esteem and confidence is closely related to her partner and family, rejection, abuse and subjugation from them, leads her entering into 
"learned helplessness cycle", causing her to tolerate more and more abuse, suffering more at the hand of partner and family. These women under study went through the same turmoil and trauma. In an attempt to prove themselves in their relationship, they became submissive, which led to getting trapped in "learned helplessness" cycle.

Submission is also a form of aggression. The suicide attempt by another participant, Pratima, was her aggression only, directed at her own self. In fact expressive aggression is all about losing control to someone else and women have been found higher in this type of aggression. All these women, participants of my study succumbed to expressive aggression at first, in an attempt to save their relationships. For some women it was a shock and social cultural set back to accept a failed relationship. Relevance of women aggression, is towards those with whom they are close, women aggression is driven by need to achieve higher level of attention from their partners especially emotional support.

Jack defined women Aggression as "A type of relatedness, a particular form of interaction, a way of connecting. It is forcefully bringing ones will, desire and voice into relationship to oppose or displace of another for either constrictive or destructive purpose." Attachment theory (Bowlby, 1983) has answer to the issue of women aggression and suggested that secure or insecure attachment relates to subjective well being, and may influence aggressive behaviour in women. Theory also stresses that when proximity and contact are threatened beyond acceptable limits, attachment is reflected in behavioural, emotional and cognitive response. Insecure attachment often results in anger, sadness, guilt dependency and aggressiveness. Bowlby (1983) further suggested that threats to proximity seeking and contacts were often seen as threats of abandonment and can lead to anger, aggression and violence. Aggression stems from a sense of loss or separation from one, with whom attachment is salient. Lack of love, insecurity rejection, threat to relationship evokes aggression and anxiety Thus aggression in these women; resulted from lack of love, abuse they faced in their relationship causing them low self esteem, anxiety, loneliness.

Another reason was the awareness and knowledge of their rights, which these women acquired. This enlightenment, that they also deserve equal status and rights, made them more aggressive. The need to be loved, to be respected within their relationship, families, society and the knowledge about their rights, made them see the gaps in their life more prominently about the kind of life they were leading and the kind of life they should be leading. This raised many questions in their minds and aroused them to revolt against injustice done to them. A stand supported by Researchers is that, women aggression is now being noticed because women are asking for freedom and equality. Also, as women are attaining power into relationship, the women movement has increased awareness about victimizations in intimate relationships. Women have realized that acceptance and forgiveness are not the only options they have, but also fighting back and defiance. Campbell has analyzed that Men have defined who can be legitimately aggressive and patriarchy has hidden aggression from women's belief in the naturalness to their subordination to men. (Campbell,1993). Feminist theories emphasized the need to understand women aggression in terms of status of women in society, to several, acknowledge and define it from woman's perspective. The power difference between Men and 
women along with women's restricted opportunities and resources contributed to an increased likelihood of women aggression in interpersonal relationships. Women aggression is located within interpersonal and institutionalized patterns of patriarchal society.

In order to understand women aggression intricacies of factors have to be understood at both micro and macro level.

Integrative contextual developmental model (White,J.W \& Kowalski, R.W) about women aggression and violence, illustrates the interaction of various factors responsible for violence against women at all levels. Contextual factors exist at cultural level and reflect the shared pattern of ideas and beliefs that exist across generations. Within this level are societal, community and neighbourhood factors .In turn these socio-cultural factors define features of social network, like family, peer group, employment etc, further embedded in these social networks are characteristics of dyadic relationship, in which violence occurs and includes traits, attitudes and motivation etc.

\section{UNDERSTANDING AGGRESSION}

Aggression was used by these women under study as survival strategy. Their aggression is similar to the life energy or 'Eros' as given by Freud in his Psycho-analytical theory or to the Drive theories which explain aggression as drive force, pursuit in each individual. General Aggression Model gives a complete holistic explanation about aggression.

General Aggression Model (GAM) given by Anderson and Bushman (2002) is a dynamic, social, cognitive developmental model which draws heavily on social-cognitive and social learning theories. Aggression depends on how an individual perceives and interprets his/her environment and people there in, expectations regarding likelihood of various out comes and knowledge and belief about how people respond in a situation. GAM relies on use of knowledge structures for perception, interpretation, decision making and action. Knowledge structure develop from experience influence all types of perception and behaviour patterns and are linked to affective states and beliefs and guide interpretation to social and physical environment Important thing is that it can become automatic with practice and one can learn the way one thinks and behave. If we look at GAM cycle, it focuses on three aspects.

Input: It consists of two proximate causes. Situational causes are features of present situation that can increase or inhibit aggression like insult, provocation etc. Personal causes include what person brings to current situation for example their attitude beliefs and behavior.

1. Present Internal state Input variables influence behavior through the present internal state and these are concerned with cognitive, affect and arousal.

2. Outcome The third stage includes several complex appraisal and decision making process ranging from relatively automatic to heavily controlled. Results from inputs enter into the appraisal and decision process through their effects on present internal state Immediate appraisal is automatized process but reappraisal is controlled process, reappraisal means alternative option has been searched and acted upon and that action may be non aggressive. In sum, aggressive behavior, like any social behavior, is result of proximate convergence of situational and personal factors. 


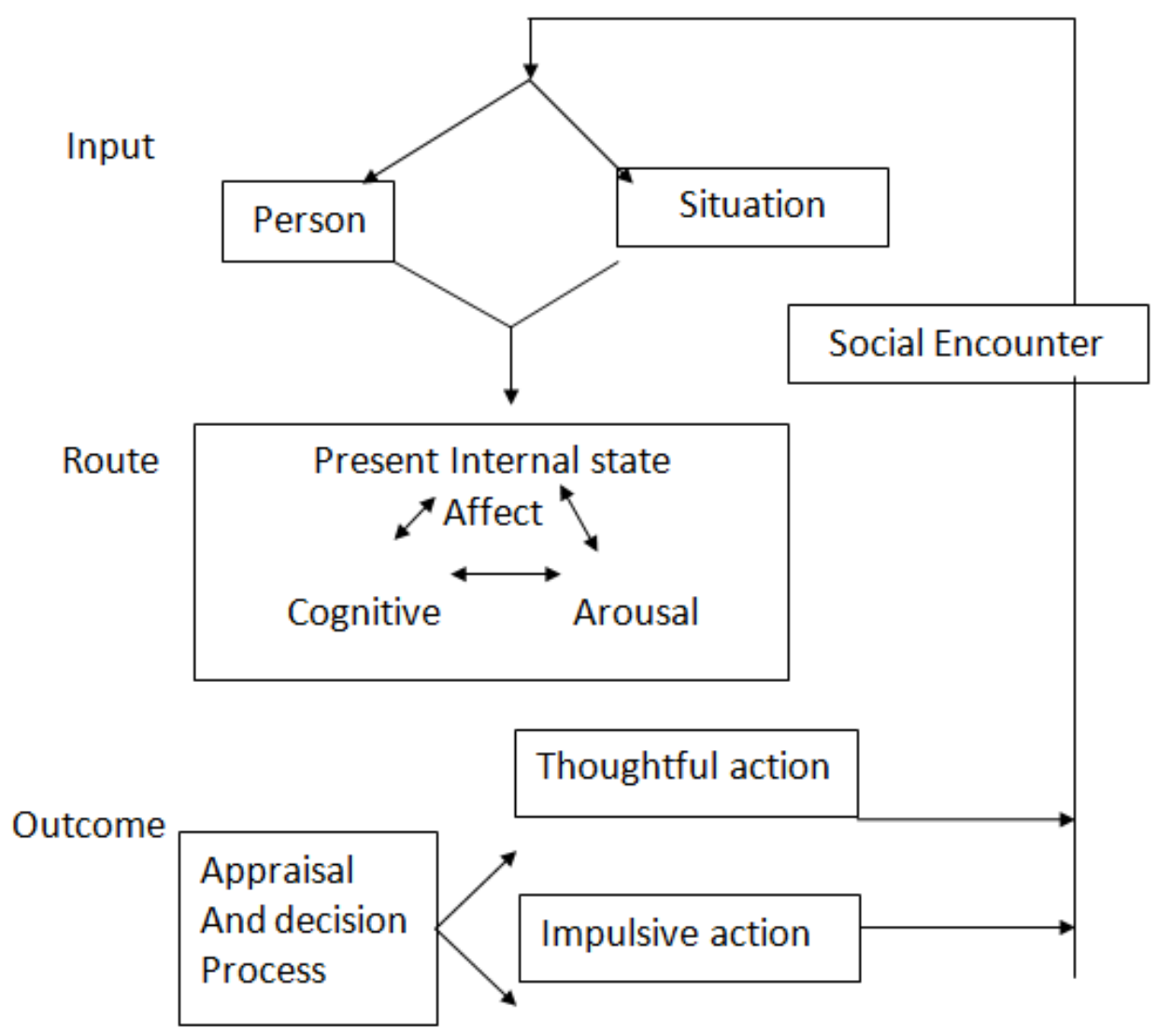

Fig 11 GAM Model (Anderson and Bushman, 2002)

This model clearly indicates that the route aggression takes, affects the outcome, whether the action is impulsive or thoughtful one.

\section{Empowerment}

Aggression inside women has been their survival strategy and they used their aggression as an instrument to achieve their goal and to gain control over their lives and situation. These women used their aggression to attain freedom, equality and justice, leading them towards empowerment. Empowerment and aggression are two sides of the same coin. Loss of control, helplessness causes aggression and attaining control, power to take decision is empowerment. Empowerment means gaining control over live. These women did the same they challenged and changed their sub ordinate status and lives. Empowerment is a process and implies redistribution of power. Empowerment does not stop here, but becomes emancipator, when it empowers others as well.

Women under study used their aggression as an instrument to attain empowerment, in personal, social and economic sphere and they did not stop at themselves, instead they reached to others and empowered other, They mustered courage to change their situation realized their strengths and decided to improve their status and position. They did not succumb to the discrimination; they derived their strengths out of it and chose to fight back. They passed through 
phases of self doubts and helplessness and sought support from their families and society, what made these women empowered was then thirst and willingness to learn and overcome obstacles. Women had restlessness to break the shackles and chains of subjugation and oppression and to live life in their own terms. They refused to accept the atrocities silently and raised their voices against it. In pursuit to find freedom, they found, rather devised ways to achieve economic independence, whether that meant learning new skills or starting their own business. Economic independence along with positive attitude towards their work and optimism brought success, which in turn helped in breaking the learned helplessness cycle. They emerged out of their self made cocoon of self pity and slowly they become confident and their self esteem was raised. Support from their family, society, meeting with likeminded people, participation in community development made them socially empowered as well. They reached to people around them, who needed help and assisted them, supported them by way of providing guidance, work, emotional support, empowering them in process. Their empowered status improved their relationships with their children, partner and families and also resulted in breaking old abusive and traumatic relationships and forming new relationships. As Naila Kabeer (1999) has said "Empowerment refers to the process by which those who have been denied the ability to make strategic life choices acquire such a ability". Strategic life choices are those, which are critical for people to live their lives. These aggressive women made their choices to end the abuse and start their life afresh. Empowerment is context-specific and relative concept therefore depends on woman's background, here circumstances and her expectations and goals. It can't measured with one single parameter, as it varies from individual to individual, and for these women also, empowerment has different meanings and colours but these colours were filled in the canvas of their life by the of brush of education.

\section{Education: Tool to achieve empowerment.}

Journey of women from aggression to empowerment had been long and ranging from one continuum to another. Their education helped them to transform their aggression to empowerment, a closer look at their lives reveal that their situation has been similar to many women, who succumbed to oppression but what made these women stand apart was their education.

Formal education or education acquired through informal and non formal means, like from religious books or from people around them, from mass media, spanning over a period of time. Whether it was kalpana, who derived strength from religious books or Promila who learned new skills, or Maya, whose dance was her strength, education and learning played important role in their lives, influencing them at deeper level and transforming their beliefs, thoughts and attitudes.

Education affected the route their aggression took which made all the difference. If we reflect on GAM, we realize that route aggression takes, is affected by cognition and affect which in turn affects the outcome. Situational factors may not be under control completely but the way, these women chose to act upon it, changed their status from being powerless to empowered. If they would have acted impulsively their aggression would have come out in hostile and reactive manner leading to destruction, but they chose the thoughtful action and utilized their aggression as an instrument to achieve their goals, the same aggression, which was aroused due to their 
unfavourable conditions become their tool to end the same unfavourable conditions. Instrumental aggression is like operant conditioning, where goal is important and is the reward. Instead of fighting violently these women made their situation favourable to gain advantage over their aggression and to improve their life, but they could do so only because of their education. Their education guided them towards this transformation. It made them aware of their strengths and weaknesses, made them sensitive towards their situation problems, knowledge about their rights, understanding of the disparities made them work towards bridging the gap and bringing the change. Their education gave them the ability to think logically, and rationally. Instead of wasting their energy, they utilized their aggressive energy purposely and systematically. After weighing pros and cons they took the actions and this wisdom and decision making ability could develop into them only because of their education. As kalpana said "Education prepares for life".

Education gives the ability to think, acquire knowledge, gain understanding and apply to practical life, to improve life. Education also influences the 'Affective 'state, concerned with emotions, which in turn help to acknowledge, accept and use emotion for benefit. Control of emotions and thoughts and their channelization leads to empowerment. The aggressive drive was used by these women as "Self Preservation" drive, as a defence mechanism to attain a free, equal status. Outcome of their aggression, when passed through the route controlled by education, was of "reappraisal", 'Conscious choice ' and 'thoughtful action'. Women moved up in the need hierarchy as described by Maslow in his "Theory of self Actualization" there by achieving high self esteem, and striving for highest need of 'self actualization', it was their education which helped them push beyond physiological and safety needs. They satisfied these primary needs, came out of their self imposed doubts, boundaries and limits and reached out to achieve higher self esteem and strived for perfection and achieving their maximum potential, by helping others they touched the self actualization paradigm, attaining emancipation. Jack (1999) has rightly said that when women use their aggression consciously and constructively for their self protection and bringing aggression positively and constructively into relationship, it results into feeling of well being, self regard and empowerment.

All I can say is that transformation of aggression to empowerment has been possible because their journey passed through channel of education, bringing changes at Cognitive, Affective and Psychomotor levels.

As discussed earlier, the social behaviours can be automatized, therefore use of thoughtful process and proactive behaviour to elicit responses for a situation can be learned and automatized, making it a natural behaviour pattern. This proactive behaviour can make aggression a positive trait, which can bring empowerment and since it's a social behaviour, it can be learned, and made a natural behaviour. Education has the ability to change the negative, destructive pursuits of aggression into positive and constructive pursuits, making it an instrument to achieve success, and this constructive aggressive behaviour can become a natural behaviour through practice.

Here I would propose an improved model of GAM by adding Education in the route,

\section{General Aggression Model in Education or GAME.}

GAME: Implications of the study 
Education affects the way a person perceives, understands and analyzes the situation, becomes sensitive towards it and acts after weighing pros and cons' in thoughtful manner. Once this process becomes a habit, it can change the personality of an individual and he/she starts acting in pro-active manner every time adverse situation arises, there by using the situation to his/her advantage. This action can become natural through practice. If these behaviour patterns can be learned at the school level, through formal education then they can help solve the problem of violence prevalent today in society. Children, who are our future, can be taught to use their aggression constructively not only to empower themselves but also to empower society, building more peaceful and empowered society at large.

The route aggression takes can be modified through education at an early stage before it reaches the output level, transforming it into constructive behaviour and slowly incorporating changes at the input level itself. This information can be helpful for the educationists to incorporate changes at various levels. Curriculum can be made to include aspects which can influence behavior, teaching methods and practices can be altered and adopted accordingly and so can be the evaluation practices. This theory of GAME has Implication in every aspect of Education, extending beyond formal territories, reaching to non formal and informal Education.

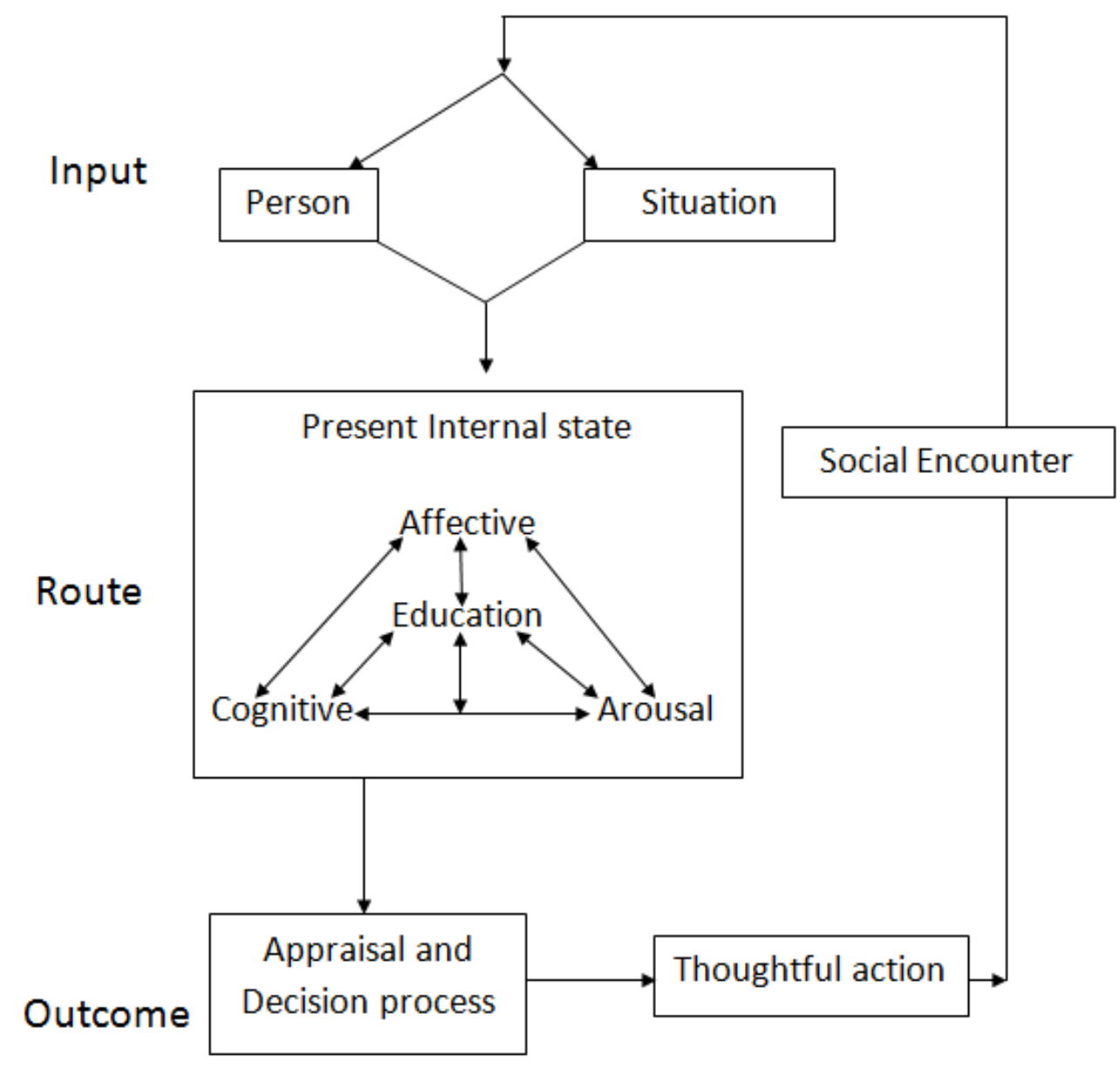

Fig 1.2 GAME: General Aggression Model In Education 
The Theory of GAME can be used by Educationists to bring changes in various aspects of Education

- Curriculum Makers can use this to build a curriculum which has subjects which can change the thinking and behavior patterns. Researchers can conduct a study on building such curriculum at different levels, Primary, Secondary and at higher level of Education.

- GAME can be used in Non formal education also which has a larger reach and influence on people. Researchers can conduct study to build programs which can incorporate these findings.

- Teaching methods and practices can be modified accordingly. Researchers can select or construct methods which can help in modifying the route aggression takes, turning it to constructive path.

- Evaluation Techniques can be changed which can help in bringing changes at output level of aggression. Studies can be conducted in this area also, leading to formulation of new practices of evaluation.

\section{REFERENCES}

1. Anderson, C.A. \& Bushman, B.J. (2002) : Human Aggression : Annual Review psychology : 53 : $27-51$.

2. Anderson, C.A. \& Bushman, B.J. (2002); Human Aggression: Annual Review psychology : 53 : $27-57$.

3. Bowlby. J. (1983): Attachment and loss : Vol. 1 : Attachment $\left(2^{\text {nd }}\right.$ Ed) : New York : Basic books.

4. Campbell, A. (1993) : Men, Women and Aggression : New York: Basic Books.

5. Charmaz, K. (2006): Constructing Grounded Theory : A Practical Guide through Qualitative analysis : London : Sage : P.P. $43-143$.

6. Cross, S.E. \& Madson, L. (1997) : Models of the self : Self construal's and gender : psychological Bulletin : $22(1): 5-37$.

7. Fehr, B., Boldwin, M, Collins, L., Patterson, S. \& Benditt R. (1999): Anger in close relationships : An interpersonal script analysis : Personality and social psychology Bulletin : 25

8. Fiebert, M.S. \& Gonzalez, D.M. (1997) : College women who initiate assaults on their male partners and the reasons offered for such behaviours : Psychological Reports : $80: 583$ - 590.

9. Glaser, B. \& Strauss, A. (1967) : The Discouvery of Grounded Theory : Strategies for Qualitative research : Chicago : Aldine.

10. Jack, D.C. (1991): Silencing the self : women and depression : Cambridge, M.A : Harward University press.

11. Jack, D.C. (1999): Behind the mask : Destruction and Creativity in women's Aggression : cambridge, M.A. : Harward univ press.

12. Kabeer, N. (1999 a) : Resources, agency, achievements : Reflections on the measurement of women's empowerment : Development and change : $30: 435-464$.

13. Kabeer, N. (1999 b) : From Feminist insight to an analytical framework : In N. Kabeer \& R. Subrahamanian (Eds): Institutions relations and outcomes: frame work and case studies for gener aware planning : New delhi : Kali for women : p.p. 3 - 48.

14. White J.W. \& Kowalski, R.M. (1994) : Deconstructing the myth of the non aggressive woman : A feminist analysis : psychology of woman Quality : 18 : 478 - 508 . 